\title{
Coastal Zone Management: Resolving Climate Change Issues Through a Statutory Framework
}

\author{
Kalpana S. Murari ${ }^{1}$ \\ ${ }^{1}$ Independent \\ Correspondence: Kalpana S. Murari, 35 / 47 'Beach Court', Arundale Beach Road, Kalakshetra Colony, Besant \\ Nagar, Chennai 600090, Tamil Nadu, India. E-mail: kalplaw@yahoo.com
}

Received: June 17, 2016

Accepted: August 9, 2016 Online Published: August 29, 2016

doi:10.5539/jms.v6n3p114

URL: http://dx.doi.org/10.5539/jms.v6n3p114

\begin{abstract}
The coastline of India is part of its valuable natural heritage that has since been severely impacted by unregulated human activities, indiscriminate urbanization and unsustainable models of development for coastal infrastructure. Climate change impacts have added to numerous causes that have left marine areas distressed and struggling for survival. Overwhelming scientific evidence suggests that undeterred by curbs on rise in global temperatures, sea levels along India's coast has continued to rise at the rate of $1.3 \mathrm{~mm}$ per year. India's coastal management program is undermined by the absence of a primary legislation, the ensuing laxity in enforcement of and compliance with regulatory norms. The present legal regime denotes a clear absence of measures to protect the natural heritage of India's coastline and coastal ecosystems. Industrial activities affecting India's coastal areas are governed by a set of legislative instruments that are sectoral in their approach and therefore seem fragmented for a cohesive battle against climate change impacts. The Coastal Regulation Zone Notification, 2011(CRZ) issued under the Environment Protection Act, 1986 does not provide adequate measures to protect threatened shorelines and marine areas. The delegated legislation falls short in regulating industrial activities along the coasts, monitoring unsustainable development of coastal infrastructure and preventing pollution at source. There is an undeniable need to constitute a legal regime for coastal management that in its core serves an agenda to address climate change impacts, enhanced by a mandate for adaptation programs. This paper will attempt to present an argument in favor of a statutory framework that will enhance the existing integrated coastal zone management plan in India and resolve conflicts arising out of economic, social and environmental issues encompassing coastal zone regulation. Climate change is forcing developing nations to usher in requisite legal reforms within their regulatory regimes that rise up to meet international standards for coastal and ocean governance.
\end{abstract}

Keywords: integrated coastal management, natural heritage, sustainable development, natural capitalism

\section{Introduction}

\subsection{Saving the Coasts to Save the Planet}

"Those of us who witness the degraded state of the environment and the suffering that comes with it cannot afford to be complacent. We continue to be restless. If we really carry the burden, we are driven to action. We cannot tire or give up. We owe it to the present and future generations of all species...." (Maathai, 2006).

Earth's ability to sustain life and economic activity remains threatened by methods of exploitation, extraction and the processing of its vast resources. Oceans, that are crucial to regulating the earth's climate, cover approximately $71 \%$ of the surface of the earth supporting $44 \%$ of the human population, serving as the largest carbon sink and reservoir of the planet. New scientific evidence reaffirms oceans' slowing ability to sequester carbon from the atmosphere resulting in the increase of its salinity and surface temperatures, and rise in sea levels. Deemed as one of the most productive habitats in the planet, oceans and coastal areas contribute substantially to the economy of a nation adding immeasurable value to its cultural and natural heritage. By 2020 it is estimated that about $75 \%$ of world's population may be living within $60 \mathrm{~km}$ of any given coastal zone, where marine and terrestrial zones merge.

Climate change speaks a global and universal language impacting all nations at varying intensities. It has left nations with diminished resilience for natural disasters experienced by coastal habitats and disintegrating ocean 
ecosystems, ultimately, eroding their value as 'natural heritage'. Aggravated by rapid and unregulated urbanization along the coasts, nations are witnessing depletion of coastal resources and the shifting of delineations of coastlines across the planet. Sea level rise and coastal erosion force a realignment of the physical landscapes of coasts, altering coastal land uses and decreasing their inherent heritage value. Coastal nations are experiencing extreme weather events that are seen to be occurring frequently and at an unprecedented scale. Nations with long coastlines are particularly vulnerable to nature's onslaught accentuating their helplessness against climate change impacts.

Well-preserved coastal habitats provide ecosystem services, which include maintaining oxygen levels in the oceanic waters and protecting coastal communities against storms and flooding. Increasing concentrations of anthropogenic carbon dioxide in the atmosphere when absorbed by the ocean become reactive making the ocean highly acidic reduces their productive capacity. Over the last fifty years oceans have been endangered by manifold increase in the number of dead zones - areas of ocean that are severely depleted in dissolved oxygen, a condition directly attributed to climate change (Global Ocean Commission).

Economic development of a nation depends on sustainable exploitation of its natural resources that call for economic efficiency, achieved through optimum utilization and replenishment of its depleting resources. Diverse sectors dependent on coastal resources appear to work with conflicting objectives, serving only cross-purposes that tend to undermine the effectiveness of present regulatory regime for coastal zone management. India faces a regulatory challenge in the establishment of effluent treatment plants along major rivers and monitor water quality discharges into the ocean despite provisions for huge subsidies and incentives. In developing nations, the absence of strong legal regimes and institutional frameworks for coastal zone management has led to unsustainable growth along the coasts that is playing a major role in sea level rise. Globalization and consequent competition for natural resources has forced coastal nations to defer enactment of adequate legislative measures to protect their coastal environment and mitigate climate change impacts.

Coastal areas that are the most vulnerable to climate change effects and serve as an indicator to the environmental health of a nation. Climate change impacts mandate a statutory framework to command and execute redevelopment of deteriorating urban waterfronts and ports, preserve and restore historically, culturally, aesthetically and ecologically rich natural heritage of our coastal areas through statutorily mandated grants and funds provided by federal government as assistance to state authorities.

\section{The Method}

The methodology used in the present paper adopts a sociological approach examining coastal laws prevalent in India and the impact of the "law in action" on society. The paper explores capability of present regulations in addressing climate change impacts along its coasts and coastal lands. The research undertakes qualitative comparisons to coastal and ocean governance laws that exist in other nations. It further discusses various international laws that impose obligations on nations to extend regulatory support in the fight against climate change by passing adequate laws on coastal governance using emerging legal concepts including sustainable development and resource management tools. These obligations are then converted to recommendations, strengthening the argument for a robust statutory framework for coastal and marine governance in India.

The paper puts forth a persuasive argument for developing nations to go beyond mere ratification of international treaties and take utilitarian steps to comply with international obligations by initiating domestic legislative measures to address climate change issues. It highlights some of the regulatory gaps that exist in the present international regime, predominantly due to scientific and technological advancements occurring at a pace, which the regulatory reforms are unable to match. Ultimately, the paper raises a clarion call on countries like India to preserve their natural heritage through appropriate statutory framework that encompasses sustainable development, resource management and adaptation programs.

\section{Discussion}

\subsection{Natural Capitalism and Natural Heritage}

A nation's identity is enhanced by its well-endowed and well-preserved natural heritage. The impact of climate change on a nation's natural heritage is likely to be profound as it causes irreversible changes to ecosystems, coastlines and physical landscapes along the coasts, and its biodiversity. The most vulnerable are the freshwater, coastal and marine ecosystems that provide ecosystem services rendering it crucial to maintain the environmental integrity of coastal habitats.

"Sustainability of our natural heritage depends on the effectiveness of meeting the challenges posed by environment and development... Sustainability expresses a desirable state for a species, and a human way of life 
to thrive; so too a country's economy. It refers to the ability to continue over time, which requires robustness against shocks." (Wilson, Furniss, \& Kimbowa, 2010)

The concept of "Natural Heritage" is defined under Article 2 of the World Heritage Convention. For the purposes of the World Heritage Convention, the following shall be considered as "natural heritage":

a) natural features consisting of physical and biological formations or groups of such formations, which are of outstanding universal value from the aesthetic or scientific point of view;

b) geological and physiographical formations and precisely delineated areas which constitute the habitat of threatened species of animals and plants of outstanding universal value from the point of view of science or conservation;

c) natural sites or precisely delineated natural areas of outstanding universal value from the point of view of science, conservation or natural beauty.

The importance of preserving natural heritage features of India's coastline serves the purpose of effective management of coastal zones and marine areas since it promotes ecosystem approach to sustainable development along coastal areas.

Business models can help balance economic growth with sustainable development by attributing a monetary value to natural resources and the ecosystem services provided by them. States acting, as trustees for the wealth of natural resources need to appropriately and adequately regulate, monitor the access and use of these resources, both by private businesses and the State. Regulations that effectively control the economic behavior of businesses through regulation of natural resources exploitation are essential to sustainable development and achieving the environmental goals of a nation.

Economic regulation is defined as the "imposition of rules by a government, backed by the use of penalties that are intended specifically to modify the economic behavior of individuals and firms in the private sector" (OECD - Glossary of Statistical Terms). Governments in developing nations must endeavor to provide stable and predictable regulatory frameworks to facilitate efficient investments, improve efficiency in the allocation of resources and promote sustainable growth using principles of Economic Regulation. Effectively, Economic Regulation tends to enhance the value of a nation's natural heritage when liability for damaging ecosystems is determined in a scientific manner and penalties are levied to act as a deterrent to violation of environmental norms.

The article, "A Road Map for Natural Capitalism” published by the Harvard Business Review (Lovins, Lovins, \& Hawken, 2006) puts forward an approach called the "natural capitalism" referring to ecosystem services provided by natural resources are the unaccounted 'natural capital' of businesses. Natural capitalism integrates ecological and economic goals of a nation to serve as a roadmap to sustainable development. The article, inter alia, suggests, shifts in business practices that call for:

a) dramatic increase in the productivity of natural resources by reducing the wasteful and destructive flow of resources from depletion to pollution... and

b) reinvesting in natural capital where businesses must restore, sustain and expand the planet's ecosystems so that they can produce their vital services and biological resources even more abundantly.

Typically, "natural capitalism" theory aims to promote principles of resource efficiency, economic efficiency and resource productivity that serve as sustainability measurement tools. The term economic efficiency refers to the process by which scarce resources are maximized to generate more productive value. A country is considered economically efficient when it uses its resources to provide products and services that exceed the monetary value of the resources. Sustainable development is one sure way to mitigate climate change impacts since it calls for resource management, waste management and resource replenishment that can offset the effects of climate change, eventually. Nations with long coastlines need to effectively tackle coastal zone management at the level of landscapes and seascapes to achieve sustainability goals through economic regulation of its natural capital.

But to invoke the concept of "natural capital", the lacuna created by the absence of an established definition for the term "coastal zone" under international law needs to be addressed. Global governance and international laws lend authenticity and emphasis to domestic legislation and aid in effective implementation. For naturalists "coastal zone" corresponds to the whole of the ecological systems, including their biotic and abiotic components (Dauvin, Lozachmeur, Capet, Dubrulle, Ghezali, \& Mesnard, 2004). The scientific community terms "coastal zones" that as interface between the land and the sea, bringing to forefront contentious issues relating to jurisdictional overlaps. World Bank defines coastal zone as "the interface where the land meets the ocean, 
encompassing shoreline environments as well as adjacent coastal waters. Its components can include river deltas, coastal plains, wetlands, beaches, sand dunes, reefs, mangrove forests, lagoons, and other coastal features. Barcelona Convention and Mediterranean Action Plan, the first ever legally binding international protocol on integrated coastal zone management provides a definition for the term: "Coastal zone means the geomorphologic area either side of the seashore in which the interaction between the marine and land parts occurs in the form of complex ecological and resource systems made up of biotic and abiotic components coexisting and interacting with human communities and relevant socio-economic activities."

\subsection{New Regimes for Newer Ventures}

Science has opened up new avenues for the commercial exploitation of marine resources lying in the high seas and the Areas Beyond National Jurisdiction (ABNJ) such as marine bioprospecting, extraction of methane hydrates, and development of marine renewables. These activities have increased the levels of threat to the marine environment and biodiversity due to the intrusive nature of their operations. There is a global call to monitor and regulate these activities to reduce the threats to ocean ecology. New forms of commercial ventures in the deep wield the proclivity to aggravate the already existing threats to oceans and coastal zones. The environmental concerns surrounding them justify the need for a new form of legal and regulatory intervention to meet the challenges posed by scientific and technological innovation. New legal tenets will evolve with a renewed agenda to address climate change, sustainable development and building a low-carbon economy (Hunter, Wold, \& Powers, 2009).

The United Nations Conference on the Law of the Sea, (UNCLOS III) referred to herein after as Law of the Sea Convention (LOSC) established navigational rights, territorial sea limits, economic jurisdiction, rights to seabed resources, management of shipping through narrow straits and the security of the marine environment. LOSC is the most comprehensive international agreement upholding three important principles, which include:

a) States own and have the geographically defined rights to certain resources in their adjacent marine areas.

b) Parts of the ocean are the 'common heritage of mankind'.

c) States are obliged to preserve the seas and accommodate the needs of other states.

These principles call upon individual nations to take steps to conserve the coastal and deep-sea resources lying within their EEZs.

The LOSC sets forth a comprehensive legal framework for the use and protection of the sea, the seabed and subsoil, and the marine environment, and includes both natural and cultural resources. With the exception of internal waters, the LOSC's regulation of all maritime zones is built upon fundamental duties of cooperation between states in order to balance competing ocean uses, and achieving climate change objectives. The Convention, inter alia, calls upon states to protect and preserve rare or fragile ecosystems; habitats of depleted, endangered or threatened marine life and prevent the spread of alien or introduced species. These international obligations are to be met by nations through appropriate domestic legal and regulatory framework. Part XII of the LOSC requires states to develop domestic legislation, adopt and enforce laws to contribute to the objectives of the Convention. International law gains significance through endorsement by parties that initiate domestic actions to validate treaty norms. Despite the breadth of intervention by the LOSC in ocean governance, it has failed to provide a global platform to enforce the implementation of its provisions or address climate change issues.

Genetic resources found in Areas Beyond National Jurisdiction (ABNJ) are to be considered the "common heritage of mankind", a concept recognized by the LOSC (Warner, 2014). Marine bioprospecting, a relatively new commercial enterprise raises questions about access rights for genetic resources and benefit sharing among states, since the commercial activity that involves marine genetic resources is not regulated beyond national jurisdiction. Marine bioprospecting relates to procuring and analyzing samples of marine genetic material, identifying potential commercial products that can be developed from them.

Marine bioprospecting and Marine Scientific Research (MSR) are two distinct avenues that need to be differentiated based on the end use of the products of these activities. It includes research information gathered from exploitation of coastal marine resources of a nation and used either for human knowledge or commercialization. There is no universally agreed definition for the term Bioprospecting. The Secretary General of the United Nations states that as per researchers, the activity involves "search for biological compounds and genetic materials of actual or potential value to various commercial applications involving series of value-adding processes, spanning several years for the purpose of isolation and characterization of active compounds." Typically, a nation's coastal management approach does not include the regulation of sedentary species found in 
the seabed or subsoil that are commercially viable, attracting investments in bioprospecting ventures. These commercial activities tend to exploit rare and fragile marine ecosystems that are natural resources of seabed but are unregulated despite the directives of the LOSC.

International Expert Group convened by Research Council of Norway states "Bioprospecting covers commercial purpose research and development, building on use of natural occurring compounds, all the way from first discovery, over patenting, benchmarking, improvement, development and commercialization." Considering the immense value in Bioprospecting, Norway has presently developed a national strategy to manage research findings from exploitation of deep-sea genetic resources. Nations that provide access to genetic resources for bioprospecting must put in place appropriate legislation and regulation to prevent unauthorized use of these resources and unsustainable means of extraction or exploitation.

In practice, deep-sea bioprospecting, most often occurs in specific habitats such as hydrothermal vents, cold seeps, submarine trenches (Leroux \& Mbengue, 2010). LOSC does not mention marine genetic resources, although the Convention on Biological Diversity (CBD) offers a definition for genetic resources under Article 2. This is the point where both the Conventions merge in regulating marine genetic resources. Under LOSC coastal states have sovereign rights to undertake, authorize, and/or supervise the exploration and commercial exploitation of marine genetic resources in their Exclusive Economic Zones (EEZs). Article 192 requires states to implement effective environmental preservation framework that can regulate bioprospecting activities within their EEZ. The international obligation of parties is further advanced by provisions of CBD adopted for conservation of biodiversity, sustainable use of its components and the fair and equitable sharing of the benefits arising out of the utilization of genetic resources. The jurisdictional scope of Article 4 of the CBD applies to areas within the limits of national jurisdiction and to processes and activities conducted, both within and beyond national jurisdiction. The CBD does not impose a direct obligation on the Contracting Parties to conserve and use sustainable methods to exploit the biodiversity in ABNJ but merely issues a mandate to cooperate directly or through competent international organizations. As technological advancements call for modernization of conservation norms, the legal and regulatory framework needs to be updated to assimilate latest ocean management tools. The Nagoya Protocol to the CBD provides for implementation of access rights and for fair and equitable sharing of benefits from the utilization of genetic resources extracted from the seabed. The Protocol sets out core obligations for its contracting Parties to take domestic measures in relation to access to genetic resources, benefit-sharing and compliance. It provides a mandate to nations providing genetic resources to extend clarity and transparency in grant of access to parties through issuance of permits by devising fair and non-arbitrary rules and procedures at the domestic levels. The Protocol sets out specific obligations on parties to support compliance with the domestic legislation or regulatory requirements of the contracting party providing genetic resources. The most significant outcome of the Protocol is that it calls upon parties to take measures to monitor the utilization of genetic resources after they leave a country including by designating effective checkpoints at any stage of the value-chain: research, development, innovation, pre-commercialization or commercialization."

Many jurists believe that the Convention on Conservation of Marine Living Resources in the Antarctica (CCAMLR) and Convention for the Conservation of Antarctic Seals (CCAS) may also apply when harvesting living organisms in the high seas and areas within the jurisdiction of a coastal nation. There have been suggestions from scholars and climate scientists to execute a binding agreement under the LOSC on the conservation of marine biodiversity in ABNJ.

A recent technological breakthrough in Japan is expected to open up large-scale exploitation of methane hydrates, a form of unconventional natural gas, making it as an important element in its long-term energy policy. Methane hydrates are produced by the decomposition of organic materials and consists of methane, a principal component of commercial natural gas, trapped in frozen water molecules as ocean sediment. The energy potential of methane hydrates reserves is expected to be greater than coal, oil and natural gas reserves. Methane hydrates are known as "fire ice" since they are highly inflammable and can be found in environments that experience high pressure and low temperatures as in ocean beds and sedimentary rocks in the Arctic. Recovery of methane from oceans is stated to be a retrograde step in our fight against climate change since methane is considered a greenhouse gas and any accidental escape into the atmosphere can push back or negate years of efforts to reduce global warming. It is feared that its extraction could lead to underwater landslides that have the propensity to trigger tsunamis. There are no standard technologies to commercially extract methane from the ocean making it cumbersome to regulate its commercial exploitation. India, which has reserves of methane hydrates along its coasts, is also awaiting the development of best available technology for methane hydrate extraction. Japan has announced plans for developing commercially viable technology for exploitation of methane hydrates by 2018 . A 
global approach for the regulation of the methane hydrate exploitation is to be envisioned and it is clear that since reserves are found within the EEZ of coastal states, a domestic regime to regulate the activity must be in place prior to commencement of its commercial production.

\subsection{Reviewing ICZM to Mitigate Climate Change Impacts}

As coasts and coastal zones play an important role in addressing climate change impacts, a stringent legal regime for management of marine and adjoining terrestrial zones becomes imperative. Marine ecosystem services are valuable to protect the life and livelihood of coastal communities and it is therefore critical that these services are not disrupted or delinked due to excessive and unsustainable means of exploitation of coastal resources. Integrated Coastal Zone Management (ICZM) is a stakeholder management approach that helps sustain ecosystem services rendered by coastal resources to a limited extent while inherently failing to mitigate climate change impacts and provide adaptation programs. Not with standing the global endorsement and development of ICZM legislation, its impact on halting or reversing the trend in degradation of coastal environments has remained negligible and the veracity of its effectiveness in addressing climate change is debatable.

The Intergovernmental Panel for Climate Change (IPCC) provides an inclusive explanation that entails the development of a domestic framework to address climate change issues within the ICZM.

ICZM provides a major opportunity to address the many issues and challenges identified above. Since it offers advantages over purely sectoral approaches, ICZM is widely recognized and promoted as the most appropriate process to deal with climate change, sea-level rise and other current and long-term coastal challenges. Enhancing adaptive capacity is an important part of ICZM. The extent to which climate change and sea-level rise are considered in coastal management plans is one useful measure of commitment to integration and sustainability. Responses to sea-level rise and climate change need to be implemented in the broader context and the wider objectives of coastal planning and management. ICZM focuses on integrating and balancing multiple objectives in the planning process. Generation of equitably distributed social and environmental benefits is a key factor in ICZM process sustainability, but is difficult to achieve. Attention is also paid to legal and institutional frameworks that support integrative planning on local and national scales. Different social groups have contrasting, and often conflicting views on the relative priorities to be given to development, the environment and social considerations, as well as short and long-term perspectives.

As per the report 'International review of ICZM' (Meltzer, 1998), this approach is still evolving, as there is no single approach to effective implementation of ICZM. With the exceptions of Ecuador and USA that have developed effective strategies to implement ICZM, most of the nations are yet to adopt policies and programs that are cross sectoral and holistic in their approach to manage marine and coastal environments. Most often, in many nations, the management of coastal zones and marine areas remains fragmented.

Numerous laws govern industrial emissions from coastal and terrestrial entities, land use changes, navigation, port management, pollution by vessels and discharge of effluents into the sea, fisheries management, deep-sea mining, and tourism. A weak statutory and institutional framework undermines the efficacy of environmental policies as it fails to recognize the existence of interdependencies among sectors. The fundamental concept that regulations pertaining to one industry cannot work in isolation of another is relevant in formulating an overarching legislation covering all industries that impact coastal zones and territorial waters. The resultant conflicts that arise out of administrative and jurisdictional overlaps at the national, regional or local levels are also resolved. ICZM can be more efficient when it adopts an ecosystem approach that is based on the principle that "conservation of ecosystem, structure and functioning, in order to maintain ecosystem services, should be a priority target of ecosystem approach and ecosystems must be managed within the limits of their functioning" (CBD). The ecosystem approach restricts human uses of coastal environment to that extent it ensures ecological limits are not transgressed and environmental integrity of coastal habitats is upheld.

The Food and Agriculture Organization (FAO) supports the development and implementation of ICZM throughout the world. Its publication on "Legislative Study of ICZM" provides guidelines to establish and strengthen national legislations for ICZM. The publication provides an insight into the future development of the ICZM law in developing nations like India that are endowed with long coastlines serving huge density of population along the coasts. According to FAO report, ICZM law refers to domestic laws that:

a) expressly or implicitly acknowledge the need for special coast-specific rules, principles or other legal mechanisms;

b) are fundamentally concerned with the sue and protection of the environment within coastal areas, which are defined to included both sea and land; and 
c) expressly or implicitly aim to achieve an approach to managing human interactions with the coastal environment in a manner that is based on an appreciation that the coast is an integrated ecological whole, and

d) that coastal management must take into account the implications of any action or proposed action for the coastal system as a whole rather than merely for any particular sector.

The FAO report, further states, the primary purpose of ICZM law is to establish a governance system that enables, facilitates and supports an integrated approach to managing human uses of coastal areas. The Organization for Economic Co-operation and Development (OECD) stated that the overall purpose of ICZM is to maximize the benefits provided by coastal zones and to minimize the conflicts and harmful effects of activities upon different maritime zones. Its goal has been defined as the production of the optimal mix of products and services from a coastal system, with 'optimal' being the mix that results in maximum social benefit (OECD, 1993). The OECD has also developed guidelines on integrated coastal management for the purpose of maintaining ecological integrity of coasts.

A comprehensive legislation for ICZM should encompass principles of intergenerational equity, sustainable development, and precautionary principle at the core and essence of its preamble. The integration of these principles within the ICZM warrants a new set of objectives that can protect the natural heritage of a nation's coastline and coastal zones that include undeveloped land and the wilderness along the coasts.

Exploration for and development of oil and gas reserves may conflict with the preservation and management of other coastal resources or their potential uses. Although the LOSC confers exclusive rights to develop seabed areas within a coastal state's territorial waters, EEZs and continental shelves, it does not offer utilitarian guidance on mineral and energy development in these areas. These areas are invariably managed under domestic legal and regulatory regimes. United States of America passed the Submerged Lands Act of 1953 that gave the coastal states exclusive rights to the resources up to 3 geographical miles from the coast establishing coastal and seaward boundaries for Federal and State governmental jurisdiction. The Outer Continental Shelf Lands Act (OCSLA), 1953 defines outer continental shelf as all lands lying seaward and outside of state waters and of which the subsoil and seabed belong to the United States and are subject to its jurisdiction and control. The primary purpose of OCSLA is "expeditious and orderly development of OCS resources, subject to environment safeguards in a manner which is consistent with the maintenance of competition and national needs."

Litigation to enforce environmental norms or violations under the statutes is more often contested under statutes like the National Environmental Policy Act (NEPA), the Endangered Species Act and Coastal Zone Management Act (CZMA). NEPA requires "federal agencies to integrate environmental values into their decision making processes by considering the environmental impacts of their proposed action and reasonable alternatives to those actions." (Environmental Protection Agency). These legislations set the regulatory trends that developing nations can very well emulate.

\subsection{Augmenting India's International Obligations}

India's effort to conserve its natural heritage is undermined by its seemingly obvious pursuit of economic goals and the inherent need to foster its ambition to be envisioned as the regional superpower. In enforcing, it's right to development India is endeavoring to maintain its ecological integrity.

India has a coastline stretching to about 7,500 kilometers interspersed with some of the largest and dense urban agglomerations with 13 major and 200 non-major ports. A significant portion of the India's economic infrastructure, including maritime facilities, petroleum industries, and other import-based units are located along the coasts with most of its oil and gas reserves found in the coastal and shallow offshore areas. The eastern coastline of India has been frequently subjected to extreme weather events causing extensive damage to lives and property and severe disruption to the ecosystem services in the coastal habitats.

The Environment Protection Act, 1986 does not explicitly spell out preservation and conservation measures for coastal and offshore marine resources. The National Plan of Action for Climate Change, 2008, has ensured India's commitment as a global player in mitigating climate change impacts. It is time for a primary legislation to protect its coastline and coastal zones that has the essentials to meet a climate change agenda with a new preamble and clearer objectives.

India's coastal zone is managed through the Coastal Regulation Zone (CRZ) Notification of 1991, is a delegated legislation promulgated under the primary legislation "The Environment Protection Act, 1986." This form of legislation fails to reach the public in a manner that enlightens them on their rights and duties encapsulated under a subordinate legislation. The power to make subordinate legislation is derived from the enabling Act. Coastal Zone Management has gained significance in addressing climate change impacts. In the present scenario, the 
scope of the parent Act or primary legislation passed in the year 1986 cannot meet the present day challenges to the regulatory regime in environment protection. The provisions of the statute seem redundant in the present circumstances where climate change and sustainable development have changed the nature of discourse on environment protection at a global level. The CRZ Notification is not completely consistent with the international legal principles of coastal zone management, as it does not endeavor to integrate coastal zone management with ocean governance. The notification works to prevent, restrict and regulate developmental activities within a landward distance of up to 500 metres from the high tide line along the coasts with no measures for preservation and conservation of ecosystems and natural heritage of the region it was expected to govern. The notification has witnessed several amendments and has failed to prevent serious violations by resource users.

In July 2004, the Ministry of Environment and Forests constituted an Expert Committee to carry out a comprehensive review of the CRZ notification. The report recommended the adoption of an integrated coastal zone management (ICZM) approach and called for a shift from a regime of regulation. The World Bank funded ICZM project implemented in India is to assist the Government of India in implementing zonal planning and management, alongside capacity building for coastal management. ICZM in India requires a legal, administrative and regulatory regime in the form of exclusive statute for decision-making and implementation of norms to serve economic and ecological purposes.

As a signatory of the LOSC, India has to pursue legislative and regulatory reforms to implement its international obligations under the LOSC and other international treaties. The Environment Protection Act, 1986, was enacted at a time when the discourse on climate change was very limited or non-existent in India, and a review of the legislation at this point in time brings to the fore the need to bring about substantive amendments to its primary objectives and its Preamble. The legislative framework has not established standards for processes and technology to be applied in various industries and, further, imposes no duty upon industries to use clean technologies or the best available technology to mitigate climate change effects. India, as a member of the Council of ISA is yet to set standards for regulation of mining activities in the high seas and develop a comprehensive legal framework as per the provisions of the LOSC.

Climate change agendas can be met through amendments to existing enactments, aligning policy objectives with climate science findings, introducing mandatory mitigation and adaptation programs. ICZM defines adaptation as "adjustment in natural or human systems to a new or changing environment. Adaptation to climate change refers to adjustment in response to actual or expected climatic stimuli or their effects, which moderates harm or exploits beneficial opportunities." In order to integrate climate change into the ICZM planning process it is crucial to ensure institutional coordination between bodies that are responsible for the implementation of mitigation and adaptation strategies, plans and programs. The global response to climate change mitigation that involve processes to reduce the release of anthropogenic greenhouse gases and adaptation programs that prepare communities for the impacts of climate change has significant implications on coastal and marine policy.

If India adopts an ICZM law, measures to monitor acquisition and development of coastal land, and regulate urbanization along the coastal territories by calling for complete prohibition of construction activity and placing restrictions on development of coastal lands, it can meet some of objectives relating to climate change mitigation. The ICZM legislation must mandate the use of environment management tools including a stringent Environment Impact Assessment (EIA), Coastal Vulnerability Assessment, Strategic Environmental Assessment (SEA) and Cumulative Impact Assessment (CIA) of sectoral activities that can help in the decision-making process over investments and development of coastal areas (Cardinale \& Greig, 2013).

Coastal vulnerability has emerged as a central concept in developing risk management strategies for coastal zone areas. In terms of coastal hazards, there are mainly three parts of vulnerability, the economic vulnerability, social vulnerability, and ecological vulnerability. "A coastal vulnerability assessment is the result of a process of identifying, quantifying, and prioritizing (or ranking) the vulnerabilities in the coastal system... Most relevant vulnerabilities in low-lying coastal zones are caused by natural hazards such as floods, drought, earthquakes and tropical cyclones." (Deltares Institute). It recognizes a vulnerability assessment as an important "first step" towards Integrated Coastal Zone Management and Development, stimulating awareness and (long term) sustainable development of coastal zones (Kaiser, 2007). The ICZM legislation should mandate environmental impact assessment of activities beyond defined boundaries that include Cumulative Impact Assessment (CIA) and Strategic Environmental Assessment (SEA) when a major project is undertaken either by private parties or by the State. A number of countries have a statutory requirement for SEA when actions are proposed across numerous sectors or when actions within a sector are likely to impact other sectors. 
The National Action Plan for Climate Change of India implores private sector to invest in adaptation programs through venture capital funds. In the absence of economic incentives to develop clean technologies and adaptation programs involving stakeholder participation, feasibility in implementing such recommendations remains low.

Finally, but prominently, the present legal regime for coastal governance in India does not address the universal problem of marine litter accumulated from various activities including aquaculture, offshore rigs, pollution from ships, urban run-off and deliberate or illegal dumping along its coasts. Marine litter invariably leads to oxygen depletion in oceans endangering the flora and fauna found within the region.

\subsection{Substantiating the Need to Replicate}

Some of the effective legislations on coastal zone management have emerged from United States, Canada and Ecuador. The Coastal Zone Management Act, 1972 (CZMA) of the USA is one such statute that provides for commercial use of the shore and contiguous maritime regions under the sovereignty or jurisdiction of USA, preventing overlapping jurisdictional conflicts, providing coordinated management and administration and balancing the conflicting interests of resource users from different industries. The CZMA has set an example by amending the preamble of original enactment to expand the existing policies to include:

a) to encourage and assist the states to exercise effectively their responsibilities in the coastal zone through the development and implementation of management programs to achieve wise use of the land and water resources of the coastal zone, giving full consideration to ecological, cultural, historic and aesthetic values as well as the needs for compatible economic development, which programs should at least provide for...

b) $\quad$...

c) The management of coastal development to minimize the loss of life and property caused by improper development in flood-prone, storm surge, geological hazard, and erosion-prone areas and in areas likely to be affected by or vulnerable to sea level rise, land subsidence, and saltwater intrusion, and by the destruction of natural protective features such as beaches, dunes, wetlands, and barrier islands

d) The management of coastal development to improve, safeguard, and restore the quality of coastal waters, and to protect natural resources and existing uses of those waters, ...

Similarly, Canada's Oceans Act shows the way to integrate oceans management with coastal zone management providing for a national oceans strategy that is based on the principles of sustainable development and precautionary approach. The Oceans Act establishes "the legal and policy basis for planning and decision-making in oceans and coastal waters, and recognizes that all three oceans are the common heritage of its citizens." The Act commits Canada to promote the understanding of oceans, ocean processes, marine ecosystems and marine resources through the ecosystem approach, as developed by the CBD that has been adopted by many international instruments. These statutes are stellar examples of legislative excellence that have conceptualized ocean governance within domestic legal regimes in the most effective format.

\subsection{Enhancing the Heritage Value of Coastal Wetlands}

Management of Marine Protected Areas (MPAs) requires a special legislation that can authorize designation of MPAs, and development of these areas and their adjacent buffer zones. MPAs are intended to protect over-exploited and vulnerable species or habitats by exerting controlling influence over human activities in the area and promoting sustainability of the natural heritage. Many deep-sea protected areas are likely to be within the exclusive economic zones of individual countries, and invariably, they provide habitats for vulnerable species and critical ecosystems on the high seas (Davies, Roberts, \& Hall-Spencer, 2007). This situation makes it critical to devise effective domestic legal frameworks to implement and enforce MPAs. Many nations are presently, designating deep-sea habitats as MPAs to mitigate the impact of climate change and reduce the damage caused by unsustainable industrial practices. Under UNCLOS, coastal states have every right to designate marine areas as protected, so long as they aim to fulfill their obligations to protect and preserve the marine environment and ensure that the living resources within the designated areas are not endangered by way of over-exploitation.

The UN Conference on Environment and Development (UNCED) negotiated and adopted a non-binding agreement, Agenda 21, a blueprint for sustainable development. Chapter 17 addresses "Protection of the Oceans, all kinds of seas, including enclosed and semi-enclosed seas, and coastal areas and the protection, rational use and development of their living resources." It further, deals with integrated management and sustainable development of coastal and marine areas and calls on coastal States to undertake "measures to maintain biological diversity and productivity of marine species under national jurisdiction... including the establishment and management of protected areas", clearly identifying MPAs as a necessary management tool for the 
protection of coastal environment.

The CBD requires State Parties to establish a system of protected areas or areas where special measures need to be taken to conserve biological diversity. The Jakarta Mandate calls for implementation of integrated coastal area management, ensuring the sustainable use of coastal and marine living resources, adoption of environmentally sustainable aquaculture practices, prevent the introduction of alien species, and establish marine and coastal protected areas.

Global Programme of Action on the Protection of the Marine Environment from Land-Based Activities (GPA) is a non-binding instrument that specifies measures that can be taken at the national, regional and global levels. The GPA recognizes that the major threats to the health, productivity and biodiversity of the marine environment are a fall out of human activities on land and in coastal areas and further inland. States are called on to identify critical habitats, including coral reefs, wetlands, seagrass, coastal lagoons, mangroves, designate MPAs and apply ICZM approaches to protect the natural heritage.

India, with its long coastline needs a specific legislation to create individual marine protected areas and establish institutional mechanisms with adequate authority and responsibility to manage and administer the area. The legal framework must ensure permanent protection of coastal and marine protected areas and restore damaged ecosystems lying within these areas. The law must manage the rampant development around protected areas to prevent adverse impacts. It must further provide incentives for compliance of laws and regulations, and fix liabilities, establish penalties for violations As part of its climate change agenda, India should decisively regulate development of coastal infrastructure and if need be, relocate existing ones into more inland areas to protect them from coastal hazards.

In India, The Wetlands (Conservation and Management) Rules, 2010, exclude coastal wetlands from the purview of its regulatory framework bringing them under the Coastal Regulation Zone Notification, which does not provide for conservation mechanisms. Wetlands are considered to be a "natural capital substitute for conventional flood control systems such as dykes, dams and embankments...." (Bassi, Kumarb, Sharmac, \& Pardha-Saradhia, 2014). Coastal wetlands include estuarine salt marshes and freshwater marshes that constitute an integral component of coastal ecology, that link dry uplands with coastal rivers, estuaries and other water bodies (Salm, Clark, \& Siirila, 2000). Research has established that inland coastal wetlands help maintain coastal water quality by balancing the salinity of coastal waters. They serve as a buffer zone shielding upland areas from storms and coastal erosion and providing habitats for critical species of waterfowl, fish and coastal animal populations. Coastal wetlands are regulated under the CRZ notification that attributes limited significance to climate change, although scientific evidence accentuates its role in regulating climate change.

A recent report prepared by the Environment Department of World Bank states "that coastal wetlands and marine ecosystems hold vast stores of carbon. Occupying only $2 \%$ of seabed area, vegetated wetlands represent $50 \%$ of carbon transfer from oceans to sediments. This carbon can remain buried in sediments for millennia. Loss of coastal wetlands and marine ecosystems mangroves leads to decreased carbon sequestration and can also lead to emissions of large amount of $\mathrm{CO}_{2}$ directly to the atmosphere..." (Crooks, Herr, Tamelander, Laffoley, \& Vandever, 2001). Currently, large-scale emissions from ecosystem degradation and habitat conversion of coastal wetlands are not accounted for in the national greenhouse gas inventories. The climate policy of India neither provides incentives for restoration nor penalties for draining or degradation of coastal wetlands and unsustainable conversion of land use, leading destruction of these habitats and ecosystems.

The international obligation imposed on developing nations to conserve and manage coastal wetlands and near-shore marine ecosystems can be implemented using the National Appropriate Mitigation Actions (NAMAs) prescribed under the Bali Action Plan of the United Nations Framework for Convention on Climate Change (UNFCCC). The Cancun Agreements, UNFCCC, 2010, adopted by parties during COP16, state that, "developing country Parties will take nationally appropriate mitigation actions ... aimed at achieving a deviation in emissions relative to business as usual emissions in 2010." This objective agreed upon for all developing countries for mitigation of greenhouse gas (GHG) emissions making NAMAs a central instrument for addressing GHG emission reductions of developing countries. India can do well by including restoration of coastal wetlands and near shore marine ecosystems within the framework of NAMAs to meet the Intergovernmental Panel of Climate Change's (IPCC) guidelines for accounting GHG emissions by sources and removals by sinks. The lack of accurate scientific evidence on sequestration of carbon and reduction of emissions from coastal wetlands and absence of applicable carbon accounting methodologies has deferred future course of action under domestic and international climate regimes. It is also claimed that the global distribution of coastal wetland peaty soils is inadequately mapped and is presumed to be largely extensive and unidentified. The IPCC report calls for more 
data and scientific research findings to understand the role of coastal wetlands in climate regulation and aid in persuading governments into taking appropriate steps to restore conserve and manage these fragile ecosystems.

Laws to regulate discharge of dredged or fill material that can diminish biological productivity of the ecosystem and monitor land-use change that involves conversion of wetlands to croplands and clearing of lands for agriculture have to be formulated to address climate change impacts.

India is a party to the Ramsar Convention, which recently broadened its scope to include climate change objectives by recognizing ecological, economic and social benefits that can be derived from wetlands. In 2002, the Ramsar Parties adopted Resolution VIII.3, which calls on Parties to manage wetlands so as to increase their resilience to climate change and extreme events. The Parties subsequently embraced climate change under the Ramsar Strategic Plan 2003-2008 as a major global challenge to conservation and wise-use of wetlands due to rise in sea levels and its temperature.

Beaches and tidelands serve as nesting areas for endangered sea turtles and are critical to many ecological services. These habitats are in dire need to be protected against coastal erosion and development of indiscriminate coastal infrastructure. India, with its long coastline and second largest beach in the world must envision a legislative framework for coastal zone management that manages coastal wetlands and includes beach enhancement and nourishment programs to restore lost and degraded beaches. An overarching and comprehensive legislation for coastal zone management, aside of managing coastal areas will add economic value to the regions and enhance their productivity.

\subsection{The Scientific Nexus to Environmental Policy Making}

Environmental policy-making is dependent on accurate, relevant, credible, peer reviewed and unbiased scientific evidence that can influence climate policy development of a nation by providing an insight into the emerging issues relating to its natural resources. Scientific information significantly affects the policy-making ability of a state and dissemination of accurate and veritable information will serve as a policy instrument providing direction and purpose. Dissemination of information on best available technologies, updated research findings, value of ecosystem services, modern conservation measures, and the long term benefits of compliance with environmental norms can help change attitudes and behaviors of resource users. Providing open access to research and scientific evidence on climate change and environmental issues can help policy makers and stakeholders participate in an informed decision-making process. Information on climate change as integrated into policies, development plans, investment plans can aid in understanding the governance aspects.

In the year 2011, the World Commission on the Ethics of Scientific Knowledge and Technology (COMEST) adopted a framework of ethical principles and Responsibilities of Climate change Adaptation. Some of the principles that may be established include:

a) Avoiding harm to the people or the environment by failing to act in response to climate change or by responding to it in an ill-considered way.

b) Fairness in the distribution of the burdens of climate change, and the benefits of appropriately responding to it, with special reference to the position of vulnerable populations, future generations, and indigenous peoples, women, and children.

c) Equitable access to vital resources, to medical, scientific and technological developments, as well as knowledge about climate change and the measures taken to adopt the same.

d) The intellectual and moral solidarity of humankind in facing the shared challenges of climate change and the consequences of climate-related disasters.

e) Environmental sustainability, understood as embracing the protection of biodiversity and the integrity of ecosystems as the very basis of life on earth.

The Framework further lists out the responsibilities of the stakeholder in respect of climate change adaptation. Some of the responsibilities are listed here for reference:

a) To establish an adequate scientific knowledge base about the causes of climate change...

b) To disseminate information about climate change adaptation that is scientifically sound and readily accessible.

c) To build the capacity for appropriate ethical reflection to enhance the ability of policy-makers and of societies in general to deal with the ethical challenges of climate change, taking into account cultural sensitivities... 
d) To protect the common heritage of humankind when developing and implementing climate change policies...

e) To develop resilient policies that can continue to function in the face of unexpected challenges brought about by climate change.

A corollary can be drawn from the legislation known as the "Fair Access to Science and Technology Research Act" or FASTR passed by the United States of America for the purpose of dissemination of scientific evidence. The law provided to facilitate "public access to and robust reuse of the results of scientific research conducted at the cost of tax payers' money. The legislation is worth replication in the context of climate science, when scientific evidence is made available to the citizens and stakeholders. Such access to authentic scientific information can shake the reverie of those who are in denial of climate science and prevent them from scoring political points. Access to accurate science can help build effective environmental leadership, which is the need of the hour.

\section{Conclusions}

A coastal area is the barometer for climate change. The vulnerability of coastal zones and ecological systems is discernible from the frequent onslaught of extreme weather events witnessed across nations. The damage to habitats, lives and property of those living in coastal nations cannot be quantified. These populations face severe storms, cyclones and typhoons that restate the increasing socio-economic pressure on populations who are clamoring for their share in coastal resources. The resilience of these coastal ecosystems has diminished due to climate change impacts. Many small island states have lost their habitats and livelihoods and are trying to survive the brutal force of nature. Coastal zones are facing the upshot of climate change across the world and it is time to efficiently manage our coasts through legal regimes that seem more evolved and in keeping with the present scientific understanding of climate science.

It is also time to revisit some of the international legal regimes on coastal management and improve upon them by reworking them to create enhanced domestic regime for ocean governance. Developing nations that are parties to international treaties should show the way forward by enforcing their international obligations through domestic frameworks for coastal management and help address climate change in a holistic manner. It is imperative to save world's coasts as a major step towards saving the planet and its inhabitants from impacts of climate change.

\section{References}

Bassi, N., Kumarb, M. D., Sharmac, A., \& Pardha-Saradhia, P. (2014). Status of wetlands in India: A review of extent, ecosystem benefits, threats and management strategies. Journal of Hydrology: Regional Studies, 2, 1-19. http://dx.doi.org/10.1016/j.ejrh.2014.07.001

Cardinale, P., \& Greig, L. (2013). Cumulative Impact Assessment and Management: Guidance for the Private Sector in Emerging Markets. Washington, DC: International Financial Corporation. World Bank Group. Retrieved from https://openknowledge.worldbank.org/handle/10986/17842

Crooks, S., Herr, D., Tamelander, J., Laffoley, D., \& Vandever, J. (2011). Mitigating climate change through restoration and management of coastal wetlands and near-shore marine ecosystems: challenges and opportunities. Environment department papers; no. 121. Marine ecosystem series. Washington, DC: World Bank. http://dx.doi.org/10.1007/s11842-010-9135-x

Dauvin, J. C., Lozachmeur, O., Capet, Y., Dubrulle, J. B., Ghezali, M., \& Mesnard, A. H. (2004). Legal tools for preserving France's natural heritage through integrated coastal zone management. Ocean \& coastal management, 47(9), 463-477. http://dx.doi.org/10.1016/j.ocecoaman.2004.09.004

Davies, A. J., Roberts, J. M., \& Hall-Spencer, J. (2007). Preserving deep-sea natural heritage: Emerging issues in offshore conservation and management. Biological Conservation, 138(3-4), 299-312. http://dx.doi.org/10.1016/j.biocon.2007.05.011.

Hunter, D., Wold, C., \& Powers, M. (2009). Climate Change and the Law (1st ed.). Newark, NJ: Lexis Nexis.

IPCC. (2007). Climate Change 2007: Impacts, Adaptation and Vulnerability: Contribution of Working Group II to the Fourth Assessment Report of the Intergovernmental Panel on Climate Change. M. L. Parry, O. F. Canziani, J. P. Palutikof, P. J. van der Linden \& C. E. Hanson (Eds.). Cambridge, UK: Cambridge University Press.

Kaiser, G. (2007). Coastal Vulnerability to Climate Change and Natural Hazards. Forum DKKV/CEDIM: Disaster Reduction in Climate Change, 15. 
Leroux, N., \& Mbengue, M. M. (2010). Deep-Sea Marine Bioprospecting under UNCLOS and the CBD. 6th ABLOS Conference, Monaco.

Lovins, A. B., Lovins, L. H., \& Hawken, P. (2006). A road map for natural capitalism. Harvard Business Review, 77(3), 145-158, 211. http://dx.doi.org/10.4135/9781446213704.n17

Maathai, W. (2006). Unbowed: A memoir. New York: Alfred A. Knopf.

Meltzer, E. (1998). International review of integrated coastal zone management. Department of Fisheries and Oceans. Oceans Conservation Report Series. Retrieved from http://www.dfo-mpo.gc.ca/Library/253987.pdf

Salm, R. V., Clark, J. R., \& Siirila, E. (2000). Marine and coastal protected areas: a guide for planners and managers. IUCN. http://dx.doi.org/10.2305/iucn.ch.2000.13.en

Warner, R. M. (2014). Conserving marine biodiversity in areas beyond national jurisdiction: co-evolution and interaction with the law of the sea. Frontiers in Marine Science, 16. http://dx.doi.org/10.3389/fmars.2014.00006

Wilson, G., Furniss, P., \& Kimbowa, R. (2010). Environment, development, and sustainability: Perspectives and cases from around the world. Oxford: Oxford University Press.

http://www.deltares.nl

http://www.unep.org/regionalseas/marinelitter/about/default.asp

www.energypost.eu/story-ice-fire-methane-hydrates-change-world/

www.gov.uk/government/publications/principles-for-economic-regulation

\section{Copyrights}

Copyright for this article is retained by the author(s), with first publication rights granted to the journal.

This is an open-access article distributed under the terms and conditions of the Creative Commons Attribution license (http://creativecommons.org/licenses/by/4.0/). 